\title{
Students' Involvement in Academic Dishonesty and Their Attitudes towards Copying in Exams and Academic Papers
}

\author{
Yona Miller ${ }^{1, *}$, Ronit Izsak $^{2}$ \\ ${ }^{1}$ School of Management, School of Education, the College for Academic Studies, Israel \\ ${ }^{2}$ School of Management, the College for Academic Studies, Israel
}

Copyright $\bigcirc 2017$ by authors, all rights reserved. Authors agree that this article remains permanently open access under the terms of the Creative Commons Attribution License 4.0 International License

\begin{abstract}
Cheating in academia is described in the literature like an epidemic, and one which crosses geographic and cultural boundaries. Academic dishonesty hurts the reputations of institutes of higher education, and carries implications for the job market as well. Some studies have attributed the spread of this phenomenon to technological advancements, which have made it much easier to locate academic content and to copy it. Our study examined students' attitudes to various forms of academic dishonesty, and the connection between demographic, personal and situational variables and the attitudes and behaviors associated with academic dishonesty. Seven hundred and seventy-nine students of business management, psychology and education completed questionnaires regarding their attitudes towards academic dishonesty and their personal involvement in academically dishonest behavior. The results showed that the infractions that were perceived as most severe were cheating on exams and in final term papers. Other acts were viewed with less severity, like letting a friend copy a paper, and referencing sources in a paper that the student has not actually read. Education and psychology students perceived cheating as more severe than did students of business management. The latter were more likely to justify copying in certain situations, like when a course is not taught clearly or an exam is hard. Hierarchical regression analysis showed that the best predictors of attitudes and behaviors are the situational factors (i.e. the characteristics of the student's academic environment). Classroom norms and the severity with which the institute treats dishonesty were found to be the factors that most strongly influenced students' attitudes and behavior. Demographic and personal variables proved less reliable as predictors.
\end{abstract}

Keywords Academic Dishonesty, Academic Misconduct, Plagiarism, Cheating Attitudes, Cheating Behavior, Business Students, Contextual Influences

\section{Introduction}

Academic dishonesty in institutes of higher education is a serious problem. Research on the topic describes the phenomenon as an epidemic, and indicates that it is on the rise (Davis et al.).[5] Academic dishonesty is harmful to the institution's ability to properly assess students' knowledge, to the relations of trust between student and school, and to those of the students who do earn their grades honestly (Jurdi et al.).[19] It also has significant long term implications, with studies indicating connections between academic fraud and later unethical behavior in the workplace (Deshpande et al. [7] Whitley \& Keith-Spiegel).[33]

Technological development has had a strong impact on academic integrity. Today's technology makes it possible to share information with millions of people simultaneously, which has changed the way people perceive the ownership of information. In the past, information was deemed to be the property of the individual who generated it. In the digital age, in which information is openly accessible to all and its source is not always clear, norms are developing that encourage the sharing of information. These norms can sometimes blur the line between academic fraud and mere "mutual assistance" with academic work (Harking \& Kubik).[14] If in the past copying was a behavior that only characterized anomalous individuals, today it is a common social phenomenon (Gross).[13]

\section{Literature Review}

Academic dishonesty constitutes an attempt to make unsanctioned use of knowledge in the completion of an academic task. Pavela [28] identified four types of fraud: 1 . cheating - the purposeful use of forbidden materials (e.g. copying from a friend or a hidden note in an exam, stealing a test, buying a paper); 2. Fabrication - purposely falsifying 
data or results to make them conform to the study's expectations; 3. Plagiarism - adopting someone else's ideas without citing the source, creating the impression that all or part of a paper belongs to the submitter when this is not the case; 4 . Facilitating academic dishonesty - helping another student perpetrate fraud (e.g. adding their name to a paper that they did not help write, allowing them to copy from your test).

It is difficult to accurately assess the extent of academic dishonesty, since most of the data is based on self-report, which is subject to a social desirability bias. Nevertheless, there is a consensus amongst researchers that the accessibility of academic materials on the internet has led to an increase in the number of instances of fraud (Ison).[16] Studies that addressed the scope of academic fraud have reported that it ranges between $20 \%$ and $90 \%$ of students, with the conclusion of various studies averaging out to approximately $75 \%$ (Josien \& Broderick).[17] In light of these numbers it is no wonder that the phenomenon is described by researchers in such serious terms as a "new epidemic," and that academic institutions are described as places in which committing fraud has become as natural as breathing, and now constitutes an academic skill - like reading and writing (Whitley).[32]

There is no accurate data available regarding the actual occurrence of academic dishonesty, but if one assumes that attitudes are a reliable indicator of behavioral intentions, and the intentions are indicators of behavior (Beck \& Ajzen) [1] looking into students' perceptions of this practice could help us understand the dynamics of the behavior in practice (Day $\&$ et al.).[6] Researchers have indeed found positive correlations between the extent of people's involvement in academic fraud and the extent to which such behavior is perceived as acceptable in certain situations (Jurdi et al.).[19] The literature has suggested a range of demographic, academic, psychological and situational factors that could potentially influence both perceptions of academic fraud and the tendency to engage in it (Jurdi et al.).[19]

\subsection{Demographic Variables}

Research has been conducted into demographic variables, like age, gender and religiosity, as possible predictors of academic fraud. Negative correlations have been found between age and the tendency to cheat (Nonis \& Swift),[27] which supports Kohlberg's theory [21] that moral development advances with age, parallel to cognitive development. Research into gender differences has yielded conflicting results. Many studies have found that women tend to cheat less than men (Nonis \& Swift) [27] while others found no gender differences at all (Chapman et al.).[3] McCabe \& Trevino [23] found that the rate of cheating amongst women has risen over the years, while that of men has remained stable. The researchers associate this result with the rise in the number of women who are studying to enter professions that have been traditionally considered "male" (e.g. business management, accounting). Studies of religious influences have also produced varying results. Several studies found that students with religious views were more ethical in their behavior (Deshpande et al., 2012),[7] while others found no difference between religious and nonreligious students (Roundy).[31]

\subsection{Academic Variables}

Studies of academic variables found that students of business management and accounting tend to engage in more academic fraud than students from other fields (McCabe et al.) [22] as well as being more forgiving of cheating (Klein et al.).[20] This difference is attributed to the socialization of these students, which focusses on business-oriented goals like competition and profit (Ely et al.).[9] Students who are at a more advanced stage in their studies have also been found to be more involved in fraud, due to their knowledge of peers who cheated and were not punished (Josien \& Broderick).[17] Negative correlations were found between students' grades and their tendency to cheat, with students whose academic achievements are lower tending to cheat more often than high achieving students (Ely et al.).[9]

\subsection{Personal and Psychological Variables}

Studies of personal and psychological factors found that individuals with an anxious or avoidant attachment style tend more towards academic dishonesty than individuals with a secure attachment style (Gillath et al.).[11] Students with higher self-efficacy tend to be less involved in cheating (Murdock \& Anderman) [26] while students motivated by extrinsic goals beyond the goal of learning (e.g. good grades and high pay) tend to be more involved than students motivated by intrinsic goals, like the desire to learn and develop their skills (Rettinger et al.).[30] Strong pressure to succeed, to meet academic requirements and to compete with peers, are all also contributing factors to academic dishonesty (Murdock \& Anderman).[26]

\subsection{Situational Factors}

Beyond the personal and psychological factors, there are additional situational factors in students' academic environment that can impact their attitudes and behaviors in the context of academic integrity. In society as a whole - and particularly in higher education institutions - there is a strong emphasis on the importance of excellence and achievement. This emphasis encourages students to perpetrate academic transgressions in order to achieve (McCabe et al.) [22] When success becomes the primary index of assessment on the one hand, and technology provides easy access to academic materials on the other, the temptation to cheat grows and stealing materials from the internet becomes an accepted norm (Reingold \& Baratz).[29]

Studies have shown that academic fraud students perceive 
academic fraud that uses digital technology as less serious than fraud that is not based on digital tools (Grieve \& Elliott).[12] It seems that the extensive use of technology in learning is changing the ethical perceptions of learners, making academic fraud more acceptable than it was before (Gross).[13]

Another influential factor is the characteristics of the academic institution - its climate and organizational culture, its enforcement methods, and the attitudes of the academic staff (Elliot et al.).[8] When an institution tends to be forgiving of academic dishonesty, such behavior is likely to increase. If, on the other hand, the organizational culture condemns and discourages academic fraud, fewer instances of the phenomenon will occur (McCabe \& Trevino).[24] Furthermore, making the students aware of the institution's policy regarding academic dishonesty impacts their tendency to engage in the behavior, since studies have shown that students who were involved in such fraud were less familiar with their institution's policy towards it (Jordan).[18] In this context it is worth asking whether students know and understand their institution's rules for the proper submission of academic assignments, whether they know what plagiarism is and whether the institution's rule about it are clear and unambiguous.

In addition to the characteristics of the institution itself, the perceived behavioral norms for acceptable behavior amongst the students are also influential factors. Students who had cheated themselves were more likely to believe that their peers were also cheating than students who had not, assuming that doing so was an acceptable norm (Jordan)[18] The influence of the students' peers and membership groups on their perceptions can be explained using Festinger's theory.[10] Students tend to justify their involvement in fraud through social comparison - i.e. "everyone else is doing it" (McCabe et al.).[22] When a student's social environment is accepting of academic dishonesty, that student will view such behavior as normal and acceptable.

In conclusion, the literature has documented a range of personal and situational factors that can influence that academic integrity of students in institutes of higher education. The goal of this study is to examine the extent to which each of these factors influences the perceptions of students towards academic dishonesty, as well as their behavior.

\section{Methodology}

\subsection{Research Questions}

The literature review provided a range of potential predictors of attitudes and behaviors related to academic dishonesty: demographic, personal, psychological and situational factors. Based on these factors, we asked the following questions:
1. Are some forms of academic fraud perceived as more or less severe than others?

2. Is there a connection between the severity attributed to a behavior and the decision to engage in it?

3. Is there a connection between individuals' age, gender and religiosity and their fraud-related perceptions and behaviors?

4. Is there a connection between individuals' personal and psychological characteristics (attachment style, self-efficacy, motivation source) and their fraud-related perceptions and behaviors?

5. Is there a connection between the situational characteristics of the academic environment and its students' fraud-related perceptions and behaviors?

\subsection{Sample and Data Collection}

The sample for this study consisted of 779 Israeli college students, studying for undergraduate and graduate degrees in one of three fields: business management (374 undergraduate, 39 graduates), education (154 undergraduate, 110 graduate) and psychology (102 undergraduates). The sample included 238 men and 541 women. Their ages ranges between 19 and 59, with an average age of $30(\mathrm{SD}=7.9)$.

The participants completed a questionnaire with 9 subscales: 1. A subscale covering demographic and academic details like gender, age, religiosity, field of study, and academic achievement. 2. A subscale covering attitudes towards different types of fraud, using a five-point Likert scale; from 1 (very ethical) to 5 (very unethical). The score for this subscale was calculated so that more severe attitudes towards fraud corresponded with higher scores (Cronbach's $\alpha=.91)$. 3. A subscale addressing the justification of academic fraud in certain circumstances, also using a five-point Likert scale; from 1 (very non-justifiable) to 5 (very justifiable). This was scored so that higher scores correlated to students' perception that a given reason was ample justification for fraud (Cronbach's $\alpha=86$ ). 4. A subscale on students' perception of the norms towards academic fraud in their academic environment using a five-point Likert scale; from 1 (strongly disagree) to 5 (strongly agree). This was scored so that higher scores correlated to a perception of fraud as more normative (Cronbach's $\alpha=.81$ ). 5. A subscale on students' perceptions of their college's policy towards cheating, using a five-point Likert scale; from 1 (strongly disagree) to 5 (strongly agree). This was scored to that higher scores correlated to perceptions of greater severity in the policy (Cronbach's $\alpha=$.76). 6. A subscale with two questions, both addressing intrinsic motivations (Cronbach's $\alpha=.91$ ) and another two questions, both addressing extrinsic motivations (Cronbach's $\alpha=.68$ ). 7. A self-efficacy subscale based on Chen et al. questionnaire,[4] using a five-point Likert scale; from 1 (strongly disagree) to 5 (strongly agree). This was scored so that as the score gets higher, the self-efficacy becomes higher, too (Cronbach's $\alpha=.74)$. 8. A subscale based on Brennan et al. 
attachment questionnaire[2] using a seven-point Likert scale; from 1 (strongly disagree) to 7 (strongly agree) (avoidant style Cronbach's $\alpha=.75$; anxious style Cronbach's $\alpha=.77$ ) 9. A subscale addressing students' perception of the extent of the academic dishonesty being perpetrated in their class, and the extent of the students' own academically dishonest behavior. All the subscales, except the self-efficacy and attachment questionnaires, were written specifically for this study.

\section{Results and Discussion}

Overall, approximately $65 \%$ of the participants reported never having been involved in academic fraud, and 35\% reported having been involved at least once. More specific comparisons between different fields revealed differences, with $45 \%$ of business management students reporting at least one instance of involvement, vs. only $32 \%$ of psychology and education students. These numbers correspond to the results of previous studies, which showed that students of business management are more involved in academic fraud and more strongly motivated by competition and the need to succeed at any price (Klein et al.).[20]

Pearson correlation was conducted to explore the connection between attitudes towards fraud and fraudulent behavior. We found a significant negative correlation between the variables $(\mathrm{r}=-.42, \mathrm{p}<.001)$, so that the more severe the students' attitudes towards academic fraud, the lower the incidence of fraudulent behavior. Moreover, we found a positive correlation between the justification of fraud in certain situations and fraudulent behavior in practice $(\mathrm{r}=.39, \mathrm{p}<.001)$. The more justifiable fraud seemed to students' in certain situations, the greater was the extent of their involvement in fraud. These results support those of previous studies, which found a positive correlation between the extent of subjects' involvement in cheating and their perception of this behavior's legitimacy (Jurdi et al.).[19] They also support the theory that there is a connection between attitudes and behavior (Beck \& Ajzen).[1]

We conducted a repeated measure Anova to determine whether there are differences in the degree of severity attributed to different types of academic fraud (for example, whether the severity attributed to copying an exam is seen as more severe than the severity attributed to copying an exercise).

We found significant differences in the degree of severity students attributed to different types of cheating ( $\mathrm{F}=54.25$, $\mathrm{p}<.001$ ). The participants were significantly less severe in their attitude towards allowing a friend to copy, adding unread sources to bibliographies, and adding the names of non-contributors to group papers. They were more severe towards copying tests and course papers, and towards buying papers online. These results call into questions the results of other studies, which showed that digital fraud is perceived as less severe than fraud perpetrated by non-digital means (Grieve \& Elliott).[12] In our study, the severity of the students' attitudes had more to do with the scope of the fraud than with the means of its achievement. Moreover, fraud perpetrated by someone else but with the assistance of the participant (e.g. letting a friend copy) was perceived more as an act of friendship than as cheating.

Table 1. Means and standard deviations of the perceived severity of different kinds of cheating

\begin{tabular}{|c|c|c|}
\hline Cheating type & SD & M \\
\hline Copying homework & 0.98 & 3.60 \\
\hline Copying tests & 0.91 & 4.30 \\
\hline Copying course paper & 0.92 & 4.25 \\
\hline Buying paper on internet & 1.10 & 4.35 \\
\hline Citing sources one has not read & 1.02 & 3.70 \\
\hline Adding a name to a group paper & 1.13 & 3.68 \\
\hline Allowing a friend to copy & 1.06 & 3.50 \\
\hline
\end{tabular}

Analysis of the demographic factors found a significant positive correlation between age and the severity of attitudes towards fraud $(\mathrm{r}=.20, \mathrm{p}<.01)$, as well as negative correlations between age and justification of fraud $(\mathrm{r}=-.26, \mathrm{p}<.001)$, and age and fraudulent behavior $(\mathrm{r}=-.20, \mathrm{p}<.01)$. These results support Kohlberg's theory (1973), according to which moral development advances with age. No significant correlation was found between religiosity and attitudes towards fraud or fraudulent behavior, which supports the results of Roundy.[31] We also found no difference in attitudes between genders, as shown in Table 2 .

Table 2. Attitude toward cheating by gender

\begin{tabular}{|c|c|c|c|c|c|}
\hline & \multicolumn{2}{|c|}{ Female } & \multicolumn{2}{c|}{ Male } & $\mathrm{T}$ \\
\hline & $\mathrm{M}$ & $\mathrm{SD}$ & $\mathrm{M}$ & $\mathrm{SD}$ & \\
\hline $\begin{array}{c}\text { Attitude toward } \\
\text { cheating }\end{array}$ & 4.00 & .65 & 3.95 & .75 & 1.25 \\
\hline $\begin{array}{c}\text { Justification of } \\
\text { cheating }\end{array}$ & 2.37 & .97 & 2.40 & 1.08 & .72 \\
\hline Cheating as norm & 2.57 & .75 & 2.56 & .79 & .03 \\
\hline
\end{tabular}

The lack of differences between genders can be explained by the fact that, with the promotion of equality in the workplace between men and women, women are becoming more pragmatic and ambitious, thus adopting behaviors that were previously more prominent in men (Mathison \& Marymount.).[25]

Analysis of academic factors found positive correlations between academic achievement and the severity of attitudes towards cheating $(\mathrm{r}=.21, \mathrm{p}<.01)$, as well as a negative correlation between achievement and involvement in academically dishonest behavior $(\mathrm{r}=-.40, \mathrm{p}<.001)$. We found differences in students' attitudes based on faculty, as shown in Table 3. 
Table 3. Attitude toward cheating by faculty

\begin{tabular}{|c|c|c|c|c|c|c|}
\hline & $\begin{array}{c}\text { Business first } \\
\text { degree }\end{array}$ & $\begin{array}{c}\text { Business } \\
\text { second degree }\end{array}$ & $\begin{array}{c}\text { Education first } \\
\text { degree }\end{array}$ & $\begin{array}{c}\text { Education } \\
\text { second degree }\end{array}$ & psychology & $\mathrm{F}$ \\
\hline Attitude toward cheating & $\begin{array}{l}3.81 \\
(.65)\end{array}$ & $\begin{array}{l}3.91 \\
(.81)\end{array}$ & $\begin{array}{l}4.18 \\
(.64)\end{array}$ & $\begin{array}{l}4.37 \\
(.55)\end{array}$ & $\begin{array}{l}4.28 \\
(.46)\end{array}$ & $27.47^{* * *}$ \\
\hline Justification of cheating & $\begin{array}{l}2.66 \\
(1.0)\end{array}$ & $\begin{array}{l}2.34 \\
(1.0)\end{array}$ & $\begin{array}{l}2.29 \\
(.96)\end{array}$ & $\begin{array}{l}1.83 \\
(.82)\end{array}$ & $\begin{array}{l}2.18 \\
(.84)\end{array}$ & $17.72 * * *$ \\
\hline Cheating as norm & $\begin{array}{l}2.78 \\
(.75)\end{array}$ & $\begin{array}{l}2.49 \\
(.85)\end{array}$ & $\begin{array}{l}2.25 \\
(.73) \\
\end{array}$ & $\begin{array}{l}2.13 \\
(.68)\end{array}$ & $\begin{array}{l}2.32 \\
(.62)\end{array}$ & $21.46^{* * *}$ \\
\hline
\end{tabular}

Undergraduate and graduate students of business management were less severe in their attitudes towards cheating than students in the other two faculties. Graduate students of education were less likely to justify cheating than students in the other two faculties. Undergraduate students of business management were most likely of the groups we tested to justify cheating, and saw cheating as more of an acceptable norm that the students of the other faculties.

Analysis of the personal and psychological factors showed significant correlations only between self-efficacy and attachment style, and between attitudes towards cheating and cheating in practice, as shown in Table 4.

Table 4. Pearson correlations between psychological traits and the research variables

\begin{tabular}{|c|c|c|}
\hline & attitude & Behavior \\
\hline Intrinsic motivation & .06 & -.06 \\
\hline Extrinsic motivation & .05 & .07 \\
\hline Self-efficacy & $.18^{* *}$ & $-.22^{* *}$ \\
\hline Avoidant style & $-.13^{*}$ & $.12^{*}$ \\
\hline Anxious style & .07 & $.10^{*}$ \\
\hline
\end{tabular}

We found a significant positive correlation between self-efficacy and the severity attributed to academic fraud, as a significant negative correlation between self-efficacy and involvement in fraud, which supports the findings of Murdock \& Anderman.[26] A significant negative correlation was found between the avoidant style and the severity attributed to fraud, while a significant positive correlation was found between the anxious style and involvement in fraudulent behavior. This corresponds to the findings of Gillath et al..[11]

We found no significant correlation between intrinsic/extrinsic motivation and students' attitudes or behaviors. In this, our results differ from those of other studies, which have found that students motivated by extrinsic goals tend to be more involved in academic fraud than students who are intrinsically motivated (Murdock \& Anderman).[26] This finding can be explained by Harter's model [15] according to which the two motivation types are independent of one another, and a person can show high or low levels of both. In the context of academic fraud, a student can have an internal interest in learning, and at the same time also have a strong desire to succeed.

Regarding the academic environment factors, we found, as expected, strong and significant correlations. These are presented in Table 5 .

Table 5. Pearson correlation between situational variables and research variables

\begin{tabular}{|c|c|c|}
\hline & attitude & Behavior \\
\hline Peers' norms & $-.61 * * *$ & $.45 * * *$ \\
\hline Organization's policy & $.13 * *$ & $-.13 * *$ \\
\hline $\begin{array}{c}\text { Awareness of } \\
\text { disciplinary code }\end{array}$ & $.20 * *$ & $-.22 * *$ \\
\hline
\end{tabular}

The data shows that the more tolerant the peers' norms were of cheating, the less severe the students' personal attitudes towards cheating tended to be. Moreover, their involvement in academic transgressions also tended to be higher. The more severe the organization's anti-cheating policy was perceived to be, and the greater the awareness of the disciplinary code, the more severe the students' attitudes towards cheating tended to be, and the less they tended to be involved in academically dishonest behavior.

We performed a hierarchical regression analysis to determine the weight of each of the factors we assessed (demographic, academic, personal, psychological, situational) in explaining the students' attitudes toward and involvement in academic fraud. The results are presented in Tables 6 and 7 .

Table 6. Hierarchical regression analysis for attitude toward academic dishonesty

\begin{tabular}{|c|c|c|c|}
\hline \multirow[t]{2}{*}{ Predictor variables } & \multicolumn{3}{|c|}{$\beta$ coefficients } \\
\hline & Step 1 & Step 2 & Step 3 \\
\hline \multicolumn{4}{|l|}{ Demographic variables } \\
\hline age & $1.93 * * *$ & .03 & .03 \\
\hline \multicolumn{4}{|l|}{ Academic variables } \\
\hline Discipline & & $.16 * * *$ & $.16^{* * *}$ \\
\hline Grades & & $.08^{*}$ & .05 \\
\hline Group norms & & $-.56 * * *$ & $-.55 * * *$ \\
\hline \multicolumn{4}{|l|}{$\begin{array}{c}\text { Psychological } \\
\text { variables }\end{array}$} \\
\hline Self-efficacy & & & .02 \\
\hline Avoidant style & & & -.04 \\
\hline $\begin{array}{c}\mathrm{F} \\
\mathrm{R}^{2} \\
\Delta \mathrm{R}^{2} \\
\end{array}$ & $\begin{array}{c}28.89 * * \\
.04 * * *\end{array}$ & $\begin{array}{c}130.15 * * * \\
.41 * * * \\
.37 * * *\end{array}$ & $\begin{array}{c}87.10 * * * \\
, 42 * * * \\
.01\end{array}$ \\
\hline
\end{tabular}

The group norms were found to be the best predictors of students' attitudes, followed by the faculty. Demographic and psychological factors were not found to be significant predictors. 
Table 7. Hierarchical regression for engagement in dishonest academic behavior

\begin{tabular}{|c|c|c|c|}
\hline Predictor variables & \multicolumn{3}{|c|}{$\beta$ coefficients } \\
\hline & Step 1 & Step 2 & Step 3 \\
\hline Demographic variables & & & \\
\hline Age & $2.51^{* * *}$ & 1.30 & 1.17 \\
\hline Academic variables & & & \\
\hline Discipline & & -.05 & $-.30^{* * *}$ \\
\hline Grades & & $-.08^{*}$ & .05 \\
\hline Group norms & & $.33^{* * *}$ & $.31^{* * *}$ \\
\hline Attitude & & $-.22^{* * *}$ & $-.21^{* * *}$ \\
\hline Psychological & & & \\
\hline variables & & & $-.12^{* *}$ \\
\hline Self-efficacy & & & -.04 \\
\hline Avoidant style & & & $80^{* * *}$ \\
\hline $\mathrm{F}$ & 6.31 & $130.15^{* * * *}$ & $.25^{* * *}$ \\
$\mathrm{R}^{2}$ & .01 & $.24^{* * *}$ & $.02^{*}$ \\
\hline$\Delta \mathrm{R}^{2}$ & &
\end{tabular}

In the case of academically dishonest behavior, group norms and faculty were once again found to be the best predictors. Attitude was found to have a significant influence on behavior, and of the psychological factors self-efficacy was found to be a significant predictor.

The results of the study show that the norms of the membership group play a central role in shaping the values of academic integrity, and that their impact is greater than that of personal and psychological factors. Indeed, many studies have shown that the central factor that determines attitudes and behavior in the context of academic dishonesty is peer norms, and that the influence of these norms outweighs that of the organization's policy and the extent to which it enforces its academic moral code (Jordan, 2001; McCabe et al.).[22]

\section{Limitations and Future Directions}

In examining academic fraud, it is difficult to accurately measure the extent of the fraud because the data are based on self-report questionnaires suffering from social desirability. Accordingly, there may be bias in the results and a wider scope of fraud. It is also possible that social desirability among education students is higher, and the difference between them and business students is affected by that. That being said, future research should use questionnaires to measure social desirability in order to examine the validity of the data.

Our study focuses on a sample based solely on one college and the indicators included in the questionnaire are designed specifically for that college as well. This may damage the external validity of the study. However, it's worth noting that the main findings in our study are largely supported by other studies made in various academic institutions in different countries. Expanding the sample to suit a variety of colleges and universities may help in getting a clearer picture of whether there are cultural differences in perceptions in relation to academic fraud.

One of the main findings of our study pointed to the influence of group norms on perceptions of academic fraud. Therefore, comparing the perceptions of students who are in a classroom setting for students in distance learning who don't belong to a learning group, is appropriate.

\section{Conclusions and Recommendations}

The results of this study indicated that a variety of factors influence students' attitudes toward academic dishonesty and their participation in academically dishonest behavior, but that the situational factors in the academic environment, especially the norms of the membership group, carry more influence than the personal and psychological factors. This result, which is supported by those of previous studies, reinforces the claim that academic fraud is a social rather than an individual phenomenon (Gross).[13] Furthermore, the students' forgiving attitude towards certain types of cheating and the ease with which they can gain access to academic information raise the question of whether the students are even aware of the rules that govern the ethics of academic work, or whether their easy access to academic material has led them to believe that it is public property (Jordan).[18] In this context, it is worth asking whether all instances of academic fraud are malicious, or whether at least some of the perpetrators are ignorant of the fact that they are doing something wrong.

In light of our findings, we suggest that the treatment of academic fraud should focus on strengthening group norms that promote academic honesty, on advertising and explaining the rules of academic ethics more clearly, and on preventing excess competition over grades. We therefore recommend the following action:

1. Encouraging a culture of academic honesty by explaining what academic fraud is and what the rules for properly using academic sources are.

2. Introducing courses and workshops in ethics to develop classroom norms based on honesty and fairness when submitting papers, and on the condemnation of fraudulent behavior.

3. Promoting a positive and supportive atmosphere that helps students achieve their academic goals, especially if those students are struggling.

4. Sending a clear and consistent message from the management and staff of the academic institution that stresses the severity of engaging in academic fraud.

5. Defining clear criteria for assessing academic tasks, making sure tests are fair and that students' workload is reasonable.

6. Writing and enforcing a disciplinary code of ethics for the institution. 


\section{REFERENCES}

[1] Beck, L., and I. Ajzen, 1991, Predicting Dishonest Actions Using the Theory of Planned Behavior. Journal of Research in Personality 25, 285-301.

[2] Brennan, K. A., C.L. Clark, and P. R. Shaver, 1998, Self-Report Measurement of Adult Attachment: An Integrative Overview. Attachment Theory and Close Relationships 46-76.

[3] Chapman, J.K., R. Davis, D. Toy, and L.Wright, 2004, Academic Integrity in the Business School Environment: I'll Get by with a Little Help from My Friends. Journal of Marketing Education, 26(3), 236-249.

[4] Chen, G., S. Gully, and D. Eden, 2001, Validation of A New General Self-Efficacy Scale. Organizational Research Methods, 4: 62-83.

[5] Davis, S.F., C.A.Grover, A.H. Becker, and L.N. McGreor, 1992, Academic Dishonesty: Prevalence, Determinants, Techniques and Punishment. Teaching of Psychology, 19: 16-20.

[6] Day, E., D. Hudson, P.R. Dobis,. and R. Waris, 2011, Student or Situation? Personality and Classroom Context as Predictors of Attitudes about Business School Cheating. Journal of Social Psychology of Education, 14: 261-282.

[7] Deshpande, S. P., J. Joseph, and K. Berry, 2012, Ethical Misconduct of Business Students: Some New Evidence. American Journal of Business Education, 5, 719-726.

[8] Elliott, T. L., L. M. Marquis, and C.S. Neal, 2013, Business Ethics Perspectives: Faculty Plagiarism and Fraud. Journal of Business Ethics, 112(1), 91-99.

[9] Ely, J.J., L. Henderson, and Y. Wachsman, 2013, Testing the Effectiveness of the University Honor Code. Academy of Educational Leadership Journal, 17: 95-104.

[10] Festinger, L., 1954, A Theory of Social Comparison and Processes. Human Relation, 7: 117-140.

[11] Gillath, O., A.K. Sesko, P.R. Shaver, and D.S. Chun, 2010, Attachment, Authenticity, and Honesty: Dispositional and Experimentally Induced Security Can Reduce Self-and Other-Deception. Journal of Personality and Social Psychology, 98, 5, 841-855.

[12] Grieve, R. and J. Elliott, 2013, Cyberfaking: I Can, So I will? Intentions to Fake in Online Psychological Testing. Cyberpsychology, Behavior and Social Networking, 16: 364-369.

[13] Gross, E.R., 2012, Clashing Values: Contemporary Views about Cheating and Plagiarism Compared to Traditional Beliefs and Practices. Education 132, 2, 435-440.

[14] Harking, A.M. and G.H. Kubik, 2010, Ethical Cheating in Formal Education. On the Horizon, 18: 138-146.

[15] Harter, S., 1981, A New Self-Report Scale of Intrinsic Versus Extrinsic Orientation in the Classroom: Motivational and Informational Components. Developmental Psychology, 17: 300-312.

[16] Ison, D. C., 2015, The Influence of the Internet on Plagiarism
Among Doctoral Dissertations: An Empirical Study. Journal of Academic Ethics, 13(2), 151-166

[17] Josien, L. and B. Broderick, 2013, Cheating in Higher Education: The Case of Multi-Methods Cheaters. Academy of Educational Leadership Journal, 17: 93-105.

[18] Jordan, A.E., 2001, College Student Cheating: The Role of Motivation, Perceived Norms, Attitudes, and Knowledge of Institutional Policy. Ethics and Behavior, 11(3), 233-247.

[19] Jurdi, R., H, S. H., and P.H.C. Henry, 2011, Academic Dishonesty in the Canadian Classroom: Behaviors of a Sample of University Students. The Canadian Journal of Higher Education, 41(3), 1-35.

[20] Klein, H., M.N. Levenburg, M. McKendall, and W. Mothersell, 2007, Cheating During the College Years: How Do Business School Students Compare? Journal of Business Ethics, 72: 197-206.

[21] Kohlberg, L., 1973, The Claim to Moral Adequacy of a Highest Stage of Moral Judgment. The Journal of Philosophy, 70: 630-646.

[22] McCabe, D.L., K.D. Butterfield, and L.K. Trevino, 2006, Academic Dishonesty in Graduate Business Programs: Prevalence, Causes, and Proposed Action. Academy of Management Learning and Education, 5(3), 294-305.

[23] McCabe, D.L. and L.K. Trevino, 1996, What We Know about Cheating in College: Longitudinal Trends and Recent Developments. Change, 28: 28-33.

[24] McCabe, D.L. and L.K. Trevino, 1997, Individual and Contextual Influences on Academic Dishonesty. Research in Higher Education, 38: 379-396.

[25] Mathison, D.L. and L. Marymount, 2010, Cheating in Business Schools, the Millennial Generation, Gender and Racial Diversity: Has the Paradigm Shifted? American Journal of Business Education, 11 (3): 111-117.

[26] Murdock, T. B. and J.B. Stephens, 2007, Is Cheating is Wrong? Students' Reasoning about Academic Dishonesty. In The Psychology of Academic Cheating, Anderman, E.A. and Murdock, T.B. (Eds.), CA: Elsevier.

[27] Nonis, S., and C. Swift, 2001, An Examination of the Relationship Between Academic Dishonesty and Workplace: A Multicampus Investigation. Journal of Education for Business, 77(2), 69-77.

[28] Pavela, G., 1997, Applying the Power of Association on Campus: A Model Code of Academic Integrity. Journal of College and University Law, 24: 97-118.

[29] Reingold, R., L. Baratz, 2011, An Institutional Code of Ethics - A Response to Attitude of Israeli Teachers' Education College Students Towards Academic Plagiarism. Us- China Education Review, Vol. 8 No 5, 589-598.

[30] Rettinger, D.A., A. E. Jorsan, and F. Peschiera, 2004, Evaluating the Motivation of Other Students to Cheat: A Vignette Experiment. Research in Higher Education, Vol. 45, No. 8, 873-890.

[31] Roundy, P.T., 2009,. Work and Religion: Artificial Dichotomy or Competing Interests? International Journal of Humanities and Social Sciences, 3 (1), 24-30. 
[32] Whitley, B. E., 1998, Factors Associated with Cheating Among College Students. Research in Higher Education, 39: 235-274.
[33] Whitley, B. E. and P. Keith-Spiegel, 2002, Academic Dishonest: An Educator's Guide. Mahwah, NJ: Lawrence Erlbaum Associates, Publishers. 